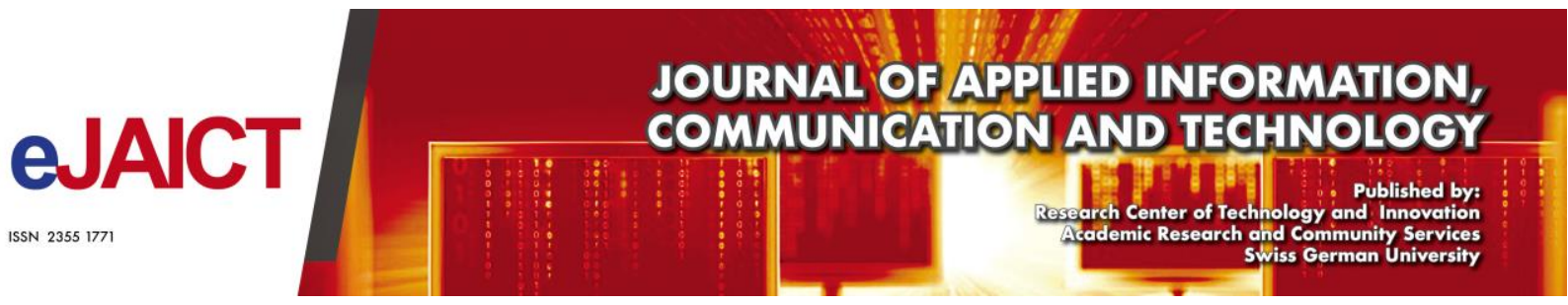

\title{
ERP Enhancement to Accommodate Business Process in Furnishing Company
}

\section{Denny Firmansyah}

Faculty of Engineering and Information Technology, Swiss German University

\section{Article Information}

Received: 13 January 2015

Accepted: 23 March 2015

Published: 25 April 2015

DOI: $10.33555 /$ ejaict.v2i1.4

Corresponding Author:

Denny Firmansyah

Email:

ISSN 2355-1771

\begin{abstract}
Avoiding customization to enhance of an ERP implementation consider as one of successful key factor. Within this paper, the writer tries to answer the question of "The expectation of ERP able to fit in with company business flow in a standard way and why enhancing the system is almost not avoidable".

To answer this question, the writer will use a case study of a furnishing distribution company or the supplier to retail store in the process of integration of ERP system with logistic process.
\end{abstract}




\section{Introduction}

\subsection{Context}

The big challenge for modern company is to optimize the supply chain, to maximize the usage of resource and customer service which align with business strategy. This is the reason to continuously implement ERP in many companies (Loizos, C., 1998). Indeed, implementation with the correct ERP will significantly reduce lot of cost; storage cost, raw material cost, delivery time, lead time and production cost (Gunn, T., 1998).

The basic principle of ERP is to build application in modular way by sharing single and common database. This create differences with previous design (application customized exist before ERP model) because nowadays data assumed standardize and shared, which eliminate lot of entry and avoidance ambiguity similar data.

The fact that not all ERP is suitable for all kind of companies, each of it has unique and specialty in management.

- Reviewing specifically rule of business to fit in with ERP. This involves preliminary beginning process and reflection must be done from project owner and good change management while in process implement ERP. Indeed, employee must be ready to see their nature of work develop, adopting new rule of business and abandon the obsolete application they use.

- Using adjustment to achieve specific development, but not to specific because this will lose the benefit of ERP. Indeed, enhancement of the system will get justify if it has benefit for the business itself (Escalle et al., 1999).

\subsection{Motivation}

Avoiding customization consider as one of critical success factor to implement an ERP (Summer, M., 1999). Customizations to enhance the system usually end up with increasing the cost and time of implementation and blocking us from the benefit to get support and upgrading offer (Janson et al., 1996). And that is the reason why all company choose an ERP implementation looking for any price to avoid specific customize the system, but still they need to enhance the system wise.

"ERP expected to adapt with company business rule and process in standardize way but why enhancement by customizing the system almost not avoidable?"

To answer above question, the writer will use case study of logistic process in a furnishing distribution company to retail store. A good example where specific enhancement is not avoidable to customize the system.

\subsection{Methodology}

Investigation conduct whiles the writer working in one of the retail store for a couple years back. The examination is to understand how they implemented their logistic process from the main distribution company in the ERP system. 


\section{ERP}

\subsection{Introduction}

A company which does not use ERP system found usually using a non-standard system which not exist in common market. To support in company business development, the system must be able to communicate one to another using interface, which tailor made by company internal team and after a certain period of time it stop to optimize.

ERP have several advantages:

- Business optimization

- Coherent and consistency information

- Integrity and uniqueness of information system

- Sharing the same information system to facilitate internal and external communication

- Minimize cost, no interface between module, simplify maintenance

- Controlling cost and time to implement and deployment

ERP allow the company to manage and optimize all the resources from production to after sales service, thru human resource, finance, logistics and sales. These complex projects leading to rethinking back of the organization, to clearly identify the needs and well plan for implementing information system.

\subsection{Definitions}

(Deixonne, J.L., 2001) For Deixonne, ERP is software solution which provide the ability to manage all company resources (human, material and finance) with focusing in two aspects; communication between business practitioner and consistency in different information. Same as (Rosemann, M.,1999) Rosemann defining ERP as a standard software solution with integrated management for all process in an organization which production planning, warehouse management, finance, human resources, etc.

ERP is a generic solution and easy to adjust or customize, develop by one editor and consist of several modules which connected one to each other and integrate the main function needed to run flow and company process (accounting and finance, logistic, business management).

Integrating business process considered as one of the main goal of ERP implementation (Brakely, H.H., 1999). ERP indeed designed to handle issue of information fragmentation in the organization (Muscatello et al., 2003). ERP in typical way integrating all business function with allowing modules to share and transfer the information freely (Hicks et al., 1995). ERP offering lot of opportunity to share information to organization in standard and centralized (Olson et al., 2005).

Furthermore, ERP recognize very effective in reducing inventory cost, increase efficiency and profitability (Appleton, E.L., 1997). ERP is also known able to reduce the time of production (Goodpasture, V., (1995). ERP possible to stock decline, reducing operational cost, information wanted by customer and ability to manage supplier company, alliance and customer as a whole. With all those benefit, ERP implemented a lot as a back bone for many organizations (Joseph et al., 2008). 


\subsection{Literature}

\subsubsection{Implementation ERP and CSF}

(Botta-Genoulaz et.al., 2005) Botta-Genoulaz, Millet, Grabot (2000) classified research literature about ERP system in six categories; ERP implementation, ERP optimization, ERP and management, ERP as a tools, ERP for supply chain management and case study. They also noted that after implementation, ERP system enhancement by customize, sociology aspect after implementation, ERP interoperability with other system and return of investment is the most active research.

ERP system is generic terms for most activity supported by multi-module software which help organization manage their resources (Teltumbde, A., 2000). But ERP implementation is a complex training and many company experience different issue in different phases. The fact is many failure cases in ERP implementation because overruns in cost and time. To lower down the failure level in implementing ERP, several researchers tried to identified critical success factor (CSF) in implementing an ERP.

CSF is a few main key areas which all things must work well, so business can be develop and company's goal achieved. "CSF for ERP implementation is brings a concept to help organization to identified critical issues which affecting implementation process. With a deep and better understanding of CSF for implementing ERP, an organization can decide the right solution to avoid the cause of the common failure of implementation (Ngai et al., 2008).

\subsubsection{Customization}

ERP provide a generic solution to customer. They can be more or less fulfill the company needs and specially if the business process of that company is unique. And later on enhancement to customize is needed. For that reason, it is important to choose an ERP which easy to adjust, eventually it will minimize the time and cost (Zhe et al., 2005). Customization is a situation where feature will be add or modify not only by parameter but also modify the application code.

Continuing a unique process is forcing company to adopt ERP enhancement and take risk to increase execution time and maintenance cost and migration in the future (Light, B., 2001). But, company must keep the minimum adjustment because every adjustment will take higher cost (Jiang, Y., 2005) and the higher adjustment of a software is also higher in the mistake.

In common enhancement of ERP customization increasing ERP coverage is increasing time and cost for implementation and this will cause the software unstable and difficult to maintain, and it is a big risk for company for stopping to operate (Thomson, J.D., 2010).

(Nah et al., 2001) a list to minimize customization is consider as one of critical success factor to implement ERP. And to minimize the needs to adjust, we need to choose in the stage of product acquisition to find the most align with organization process (José et al.).

A new version of ERP probably covering a new feature which against with the changes been made or remove the structure needed in the system itself (Carlino et al., 2000). That is 
one of the reasons why organization which implement ERP try to maximize to adopt features offer by the ERP instead of changing the application to fulfill the specific business practice (Parr et al., 1999).

\section{Case Study}

\subsection{Introduction}

In the phase of needs analysis, logistic process been analyzed thru several discussion with the process owner. This phase helping to examine data in detail needed for logistic process chosen to implement next in ERP. In this initial stage, several feature needed is not supported in standard ERP but the feature function requested is very much important for the continuity of the business itself.

The use of specific development was finally chosen. Significantly it causing long delay in development due to specific enhancement was not anticipated previously.

After rolling the test phase, the project managed to produce. But several request to change in the system wise arise after production to make sure continuity operator services. In this stage, all must realize that change management will be difficult due to specific customization.

To understand the reason for specific development, firstly we must know the concept of "classic logistic", and then the writer will try to explain the unsupported feature.

\subsection{Description of "Classic Logistic"}

Most of companies regardless the sector, continuity of procuring the items from the supplier for ready to sell and this items is keep in the location define well in the warehouse. Implementation of "classic logistic" is almost standard for all ERP.

ERP use an idea filling an item to present the item must have a unique code to identify among other item code, count base on unit measurement and follow by unique shipping number.

After deciding the supplier, purchase order transaction will cover the item code, quantity order and item measurement. When receiving the goods, transaction must enter the item code which really delivers by the supplier, following the quantity and shipping number for every unit deliver by supplier.

The goods received send to defined location in a warehouse, it can be relocate or directly to sell to customers. Also for selling transaction must have this information completed.

The similarities for above different transactions that they all are use the same following information below:

- Item code

- Quantity

- Unit of Measurement

- Retail Logistic Detail Parameter Information

- Shipping Number (for receiving \& shipping process) 
Almost all ERP use the same above set of information.

\subsection{Description of "Retail Logistic"}

Operation in furnishing retail logistic is almost the same as classic logistic, but it has a several different features.

Several different features identified:

- Per each purchase order has "status" which showing the latest status per each item ordered

- Each purchase order will attach with "container number", one container can consist of several purchase orders

- Several small size items pack in one pallet, the big item can be pack in one pallet

- Several pallet of items count into one consignment

- And a container will stack in with one or several consignment of items

- Attached with single or several deliver shipping number

In general case it can be assume the issues arise in furnishing logistic can be appearing in other sector as well. The concept of item modeled in ERP limited only in structural component (code, series number) which represent physical component, the other part of information described above is not supported in standard module for general ERP.

\subsection{Issue Formalization}

The goal of supply chain management is to provide the right product on the right time in the right place and low cost. This show a product journey is the primary main focus for supply chain management.

ERP use generic term of "item" to model the product or the goods to be sold to customer, an item is identified as a code. Besides that, ERP allow to manage stocks which can only be defines as all items belong to the company.

Inventory management goal is to know when all the items available in the company. To get that information company need to provide physical accounting which able to count input and output from all of items to provide a report anytime get updated.

- Item Input; this operation is allow to count item input into store, receiving item which ready to sell to customer. Stock manager responsible to renew total item by increasing initial quantity with received quantity.

- Item Output; this operation is consist of deletion item stock align according with order or sales transaction. And for input, stock manager must renew quantity by reducing output quantity from initial quantity.

- Inventory Report; stock manager must be able to provide anytime. This type of report must show certain situation, quantity and stock location.

Stock quantity is the result from differences between input and output flow for certain period of time. 


$$
\begin{aligned}
& S_{a}\left(t_{n}\right)=S_{a}\left(t_{n-1}\right)+I_{a}[q]-O_{a}[q] \\
& S_{a}\left(t_{n}\right) \text { : is the stock (or quantity) of the item (a) at time (tn) } \\
& S_{a}\left(t_{n}-1\right) \text { : is the stock (or quantity) of the item (a) at time ( }\left(t_{n}-1\right) \\
& l_{a}[q] \text { : is the item irput of the quantity }(q) \text { of the item (a) } \\
& \mathrm{O}_{a}[q] \text { : is the item ouput of the quantity }(q) \text { of tie item (a) }
\end{aligned}
$$

Fig. 1. Inventory Formula in All ERP

Above formulation is supported as a standard inventory formula in all ERP. In ERP provide an input screen area to enter item information needed, other screen is allowing input / output item transaction which affecting the stock quantity available according above formula.

We are not discussing about input / output operation without mentioning other main production operation, the completeness detail information align with supply chain journey from the supplier to the store. Indeed ERP using concept of receiving and shipment if needed, but in the general standard design flow, most of information is not capture in the system.

It was explained informally in previous chapter the logistic issue raised in furnishing logistic is heading to specific enhancement of the system wise.

\section{Conclusion}

It is clear that these days many company looking very hard for a standard solution without or very less to enhance a specific customization which causing unsupported scalability information system and directly impact with business continuity life cycle.

Thanks to advanced technology in ERP today, now it become an essential tools for a company to be more flexible and responsive. And this is the reason for editor and integrator share the advice to always present an ERP with a flexible and global solution and able to respond all business process in standardize way. Until this part is correct, but still many case arise for example the case or issue describe within this paper.

Experience show that all companies who runs ERP is inevitably have to face the fact that they have to execute the option to reengineering the business process and adjust due to adapting the changes or enhancement which conflicted with standard business rules. The practices will even more difficult if the enhancement which critical to business is not supported in the business rule. It is not deniable that reengineering the business process adopting from the best practice of an ERP is still the best solution.

If the business rule is relevant and important to the company, customization to enhance the system is inevitable, as in this case study where the rule of business very specific for furnishing business. As mentioned above, enhancement with specific customization it is not a cheap, development and high maintenance cost will be applied.

Research community with a unanimously consider minimizing customization to enhance the ERP as a critical successful factor is strong related with ERP implementation result. It 
is advisable for themodern company to stay competitive with the consideration for uniqueness of the business process which not present in standard or not supported by ERP.

\section{References}

Appleton, E.L. (1997). How to survive ERP. Datamation, 43(3), 50-53.

Botta-Genoulaz, V., Millet, P.-A., Grabot, B. (2005). A survey on the recent research literature on ERP systems, Computers in Industry 56 (2005) 510-522.

Brakely, H.H. (1999). What makes ERP effective? Manufacturing Systems, 17(3), 120.

Carlino, J., Nelson, S., Smith, N. (2000). "AMR research predicts enterprise applications market will reach $\$ 78$ billion by 2004 ", AMR research, Boston.

Chen, I. J. (2001). Planning for ERP systems: Analysis and future trend. Business Process Management Journal: 7(5), 374-386.

Deixonne, J.L. (2001). Piloter un projet ERP. Dunod.

Escalle, C.X., Cotteleer, M.J. (1999). Enterprise Resource Planning. Technology Note, HBS case \#9-699-020, Harvard Business School.

Goodpasture, V. (1995). Easton steps up to the plate. Manufacturing Systems, 13(9), 58 64.

Gunn, T. (1998)"People: The Primary Resource in World Class Manufacturing," CIM Review, 4, 3, 1998, pp. 6-9.

Hicks, D. A., Stecke, K.E. (1995). The ERP Maze: Enterprise resource planning and other production and inventory control software. IIE Solutions, 27(8), 12-16.

Janson, M.A., Subramanian, A. "Packaged Software: Selection and Implementation Policies", INFOR, 34, 2, 1996, pp. 133-151.

Jiang, Y. (2005). Critical Success Factors in ERP Implementation in Finland, M.Sc. Thesis In Accounting, The Swedish School of Economics and Business Administration.

José, E., Joan P. Enterprise Resource Planning Systems Research: An Annotated Bibliography. Communications Of The Association For Information Systems.

Joseph, M.R., Chen, I.J. (2008). Enterprise resource Planning (ERP) Implementations: theory and Practice, International Journal of Enterprise Information Systems, Volume 4, Issue 1.

Light, B. (2001). The maintenance implications of the customization of ERP software, J. Software Maintenance: Res. Practice 13 (2001) 415-429. 
Loizos, C. (1998). “ERP: Is it the Ultimate Software Solution?”, 1998, pp. 33-48.

Muscatello, J.R., Small, M.H., Chen, I.J. (2003). Implementing enterprise resource planning (ERP) systems in small and midsize manufacturing firms. International Journal of Operations and Production Management, 23(8), 850-871.

Mustapha, E.M., Samir, B., Alami, S. (2012). Enterprise Resource Planning (ERP) and Integration of Purchase, Inventory and Sale processes: Proposition of a Common Minimal Model. IJCSI International Journal of Computer Science Issues, Vol. 9, Issue 5, No 1, September 2012.

Nah, F., Lau, J., Kuang, J. (2001). Critical factors for successful implementation of enterprise systems. Business Process Management Journal, 7(3), 285-296.

Ngai, E.W.T., Law, C.C.H., Wat, F.K.T. (2008). Examining the critical success factors in the adoption of enterprise resource planning, Computers in Industry.

Olson, D.L., Chae, B., Sheu, C. (2005). Issues in multinational ERP implementations. International Journal of Services and Operations Management, 1(1), 7-21.

Parr, A., Shanks, G., Darke, P. (1999). "Identification of Necessary Factors for successful Implementation of ERP Systems". New information technologies in organizational processes - field studies and theoretical reflections on the future of work. Kluwer Academic Publishers: chapter 8, pp. 99-119.

Rosemann, M. (1999). ERP-software - characteristics and consequences 7th Europan Conference on Information Systems, Copenhagen, Denmark.

Summer, M. (1999). "Critical Success Factors in Enterprise Wide Information Management Systems". Proceedings of the Americas Conference on Information Systems, Milwaukee, WI, 1999, pp 232-234.

Teltumbde, A. (2000). A framework for evaluating ERP projects. International Journal of Production Research 38 (2000) 4507-4520.

Thomson, J.D. (2010). Practical Studies In E-Governance: An Empirical Exploration Of Enterprise Resource Planning,International Review of Business Research Papers Vol.6, No.1, Pp.432-466.

Zhe, Z., Matthew K.O., Lee, P.H., Liang, Z., Xiaoyuan, H. (2005). A framework of ERP systems implementation success in China: An empirical study, Int. J. Production Economics 98 (2005) 56-80. 